
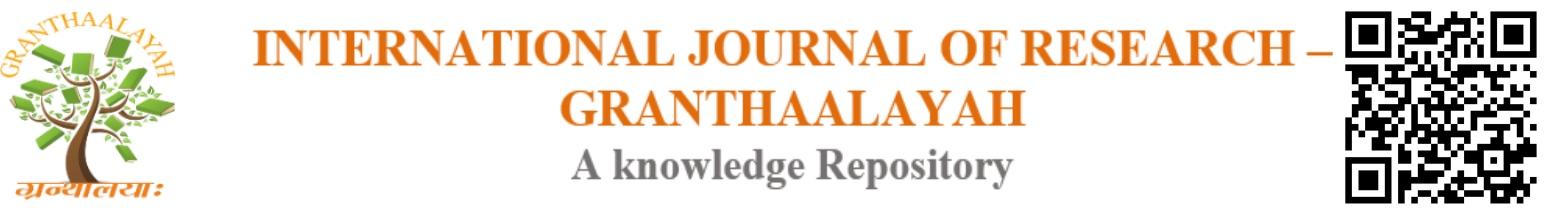

Science

\title{
SCALED CELL CARCINOMA TYPE VERRUCOUS INFILTRATED - CASE STUDY
}

\author{
Dr. Xavier Antonio Chan Gómez ${ }^{1}$, Dr. Jorge Daher Nader ${ }^{2}$, Alida Bella Vallejo López ${ }^{3}$ \\ ${ }^{1}$ University of Guayaquil, Faculty of Medical Sciences, Guayaquil, Ecuador \\ ${ }^{2,3}$ MSC, University of Guayaquil, Faculty of Medical Sciences, Guayaquil, Ecuador
}

\begin{abstract}
Disorders in patients who develop squamous cell carcinoma can lead to severe conditions. The present case study evidences the advance of this pathology in a patient who goes to the medical services when the problem has advanced.

Objective- To describe the case of a patient who underwent surgery to remove a tumor from the vulvar region to prevent it from triggering in severe states.

Method - Surgery of a vulvar tumor, performed on a female patient of 62 years.

Result- Squamous cell carcinoma, infiltrative verrucous type, with dimensions of $7 \times 6 \mathrm{~cm}$, with an invasion depth of $2.7 \mathrm{~mm}$ in the central region

Conclusion- This type of pathology should not be allowed to worsen when it occurs, as it deteriorates the quality of life of patients over the years. If it is detected and treated early, complications can be avoided. In the present case, the histopathological diagnosis was epidermoid carcinoma. It is expected that the information collected will be useful to professionals and that it contributes as an alert to detect early health problems in patients.
\end{abstract}

Keywords: Carcinoma; Epidermoid; Surgery.

Cite This Article: Dr. Xavier Antonio Chan Gómez, Dr. Jorge Daher Nader, and Alida Bella Vallejo López. (2019). "SCALED CELL CARCINOMA TYPE VERRUCOUS INFILTRATED - CASE STUDY." International Journal of Research - Granthaalayah, 7(3), 11-16. https://doi.org/10.29121/granthaalayah.v7.i3.2019.938.

\section{Introduction}

Squamous cell carcinoma of the vulva begins in the thin, smooth cells that line the surface of the vulva. Most vulvar tumors are squamous cell carcinomas. Vulvar cancer is a type of cancer that affects the outer surface of the female genitals.

The vulva is the area of skin that surrounds the urethra and vagina, includes the clitoris and the lips. In general, vulvar cancer manifests as a bump or sore on the vulva that often causes itching. Although it can occur at any age, vulvar cancer is diagnosed more frequently in older adults. Treatment for vulvar cancer usually involves surgery to remove the cancer and a small part of the 
healthy tissue around it. Sometimes, vulvar cancer surgery requires the removal of the entire vulva. The sooner vulvar cancer is diagnosed, the less likely it is that the treatment will require more extensive surgery.1

Vulvar cancer is a disease of biopsychosocial impact that requires early diagnosis. 2 Vulvar neoplasms are rare. They usually occur in menopausal patients; According to the stage in which the diagnosis is made, the patient may have a better prognosis. In these vulvar conditions it is essential that the gynecologist has these neoplasms in order to evaluate the presence of lesions and perform the corresponding biopsies for diagnosis and correct treatment. Vulvar cancer is the fourth most frequent neoplasm of the genital tract after cancer of the endometrium, cervix and ovary. 3 The most frequent histological type is squamous cell carcinoma of the vulva, which constitutes $90 \%$ of vulvar cancer cases. 4

The most common location, even in $80 \%$ of cases, are the lips (60\% greater), the clitoris (5-15\%) and in $10 \%$ of the cases they are multifocal. The etiology remains unknown; However, in recent years a debate has opened up about two completely different pathways of carcinogenesis, one of them related to HPV and the other with a chronic inflammatory process, so that two different profiles of patients could be found, with different factors of risk and natural history, but with the same diagnosis 5-6. A problem with this type of tumor is that the diagnosis is often established in advanced stages due to lack of consultation with the doctor because they are classified erroneously as non-oncological lesions. 7

The World Health Organization (WHO) in 1994 published the 2nd Edition of the "Histological classification of tumors of the female genital tract" in which it introduces the term "squamous intraepithelial lesion" (SIL) that covers both the dysplastic lesions and the carcinoma in situ.8 The WHO defines SIL as the alteration of maturation and nuclear abnormalities, such as the loss of polarity, pleomorphism, thickening of nuclear chromatin, irregularities of the nuclear membrane and mitotic figures, and the need to add whether HPV is involved in the injury. 9

The cause of vulvar carcinoma is not known. The ac begins when a cell produces mutations in DNA. And these mutations allow cell growth and fractionate rapidly. The cell and the product of the divisions continue to live when other normal cells would die. The accumulated cells form a tumor that can be cancerous and that invades the surrounding tissues and spreads to other parts of the body. Older age. The risk of vulva ca increases with family history, precancerous pathologies and especially with advanced age, although you can suffer at any stage of life. The average age of diagnosis is 60 to 65 years. Also the exposure to HPV virus of the human papilloma sexually transmitted, related, especially with the oncogenic subtypes 16 and 18.

Injuries in the lower genital tract, number of partners, early onset of sexual intercourse and a history of sexually transmitted infections which increase the risk of suffering from various types of ac, such as vulva. Tobacco use increases risks. Another factor to consider is a weak immune system or Ingest medications that suppress the immune system, such as corticosteroids, or patients with HIV. Lichen sclerosus, which causes smoothing and itching of the skin of the vulva, increases the risk. In patients older than 70 years, vulvar carcinoma is associated with a history of chronic inflammation, irritative vulvitis, and the presence of lichen sclerosus or epithelial hyperplasia. 
Although tumors of the vulva occur in a visible external area of the woman's body surface and produce typical symptoms of irritation and pruritus, their diagnosis does not occur in the necessary time. It is a diagnosis that is made in a second place, and in the first place.

\section{Material and Method}

This article reports the case of a 62-year-old woman who visited the medical center for another health problem, and examined if a tumor mass is observed in the vulvar region, after obtaining data for the clinical history. can determine what was necessary to remove the tumor mass and perform a histopathological study. The initial diagnosis was invasive vulvar cancer; Regarding the case, the bibliography is reviewed. The patient was scheduled in November 2018 for the groups Total Vulvectomy for Cancer of the vulva in the Valdéz Pavilion of the Luis Vernaza Hospital, before surgery, sterile fields, surgical and the necessary instruments were placed, the main surgeon, Doctor Plaza, and 3 doctors, among them Dr. Chan, with the anesthetized patient, the professionals in the surgical procedure of the attention area, extracting and cauterizing the part of the patient's left posterior side, against the hands of the clock. Removing all the tissue with the same name: labia majora, labia minora, appendages of the inside of the vulva, sinister, communication, communication and applications in the field. In this case, jelonet's attachment in the vagina is also found.

\section{Results}

Diagnosis: Total Cleaning Vulvectomy. The report of the Indica Histopathological Laboratory, is vulva that measures $6.5 \times 3.7 \times 1 \mathrm{~cm}$, of violet color, it has a deep face of adipose tissue. The sample marked with suture thread that indicates the clinician treating the clitorine area. a tumor lesion measuring $7 \times 6 \mathrm{~cm} \mathrm{x3,8,} \mathrm{corresponding} \mathrm{to} \mathrm{the} \mathrm{lower} \mathrm{third} \mathrm{of} \mathrm{the} \mathrm{vulva,} \mathrm{exophytic,} \mathrm{irregular}$ surface poorly defined edges, grayish-white, friable consistency is observed that the cut infiltrates the entire thickness of the skin, adipose tissue and that is in contact with the deep surgical border (H5): the rest of the internal surface of the vulva is grayish brown with an elastic consistency.

- 1A1: Tumor with right lip plus surgical border.

- $1 \mathrm{~A} 2$ Tumor with left lip plus surgical border.

- $1 \mathrm{~A} 3$ Surgical edge of the tumor.

- 1A4 Tumor with deep surgical border.

- 1A5 1 A 61 A 71 A 81 A 91 A 10 different tumor sections.

- 1 A 11 Surgical border of the right upper lip.

- 1 A 12 Surgical border of the left upper lip.

The examined sections show keratinized stratified epithelium lining with an exo endophytic growth pattern, with neo-verrucous formations lined by epithelium whose lower two thirds of the clustered cells lack cell maturation, the nuclei are interchromatic, pleomorphic, increase of mitosis whose superficial third shows maturation cellular with prominent koilocytosis, hyperkeratosis, paraqueatois, hypergranulosis, which alternates with intraepithelial growth with elongation and anastomosis of epithelial ridges, shows epithelium with pleomorphisms, cells with bulky nuclei, vesicles, prominent nucleoli, cytoplasm, acidophilus, which presents infiltration in the central region of the lip, characterized by small accumulations of neoplastic cells, which infiltrate $2.7 \mathrm{~mm}$ 
deep, in the superficial and deep dermis, surrounded by intense lympho-monocyte inflammatory infiltrates that form accumulations, that does not involve the deep surgical border, where muscular and adipose tissue with capillary congestion is observed.

The extension of the lesion is $7 \times 6 \mathrm{~cm}$, the upper surgical edges of the right and left lip (labeled: 1 to 10,1 to 11 show acanthosis, hyperkeratosis, the rest of the surgical margins show neoplastic infiltration)

The prognosis after the intervention was favorable to continue the treatment, however, the patient refused to continue with her treatment.

\section{ANEXOS}

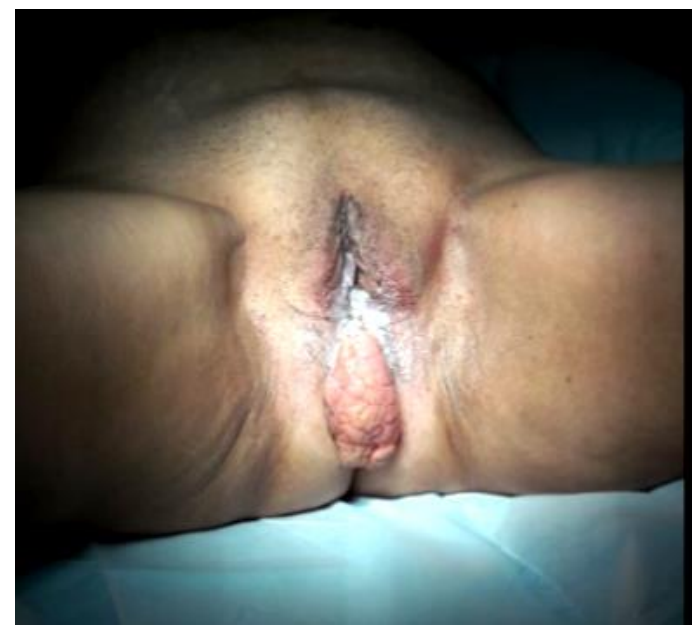

Sight without vulvar area or carcinoma

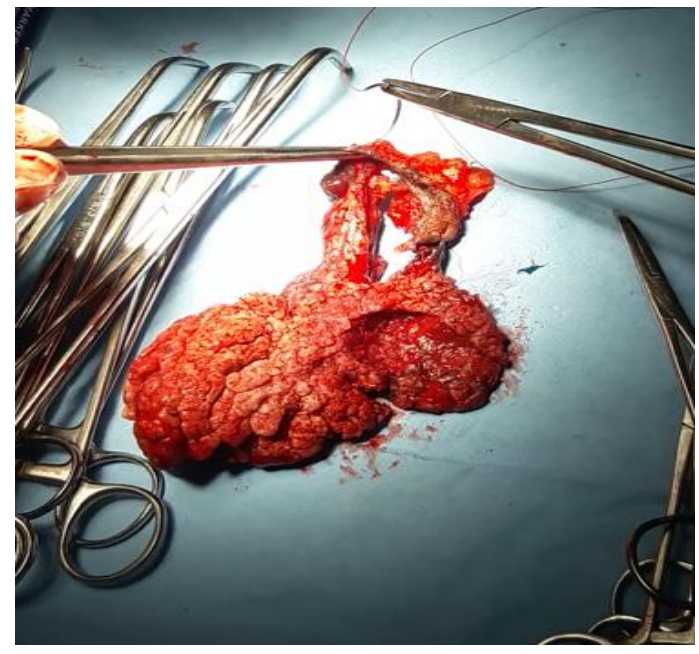

Total carcinoma resection

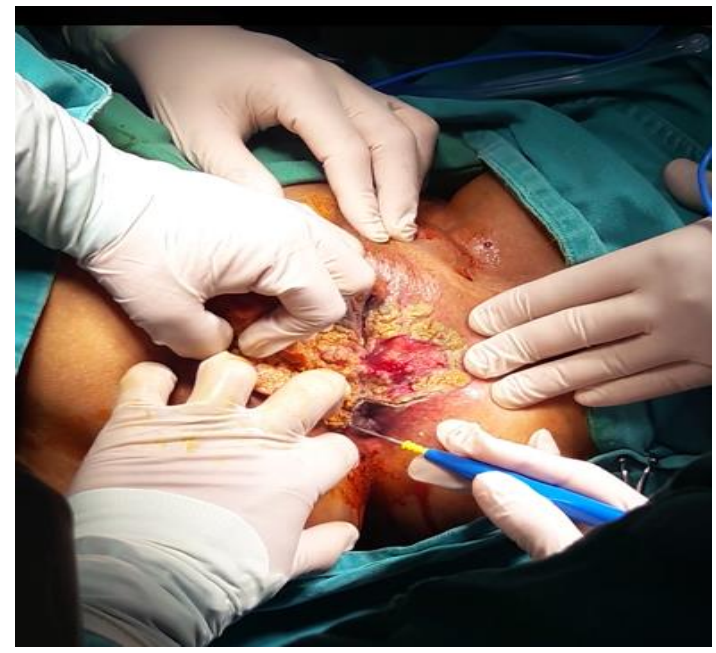

Total carcinoma resection

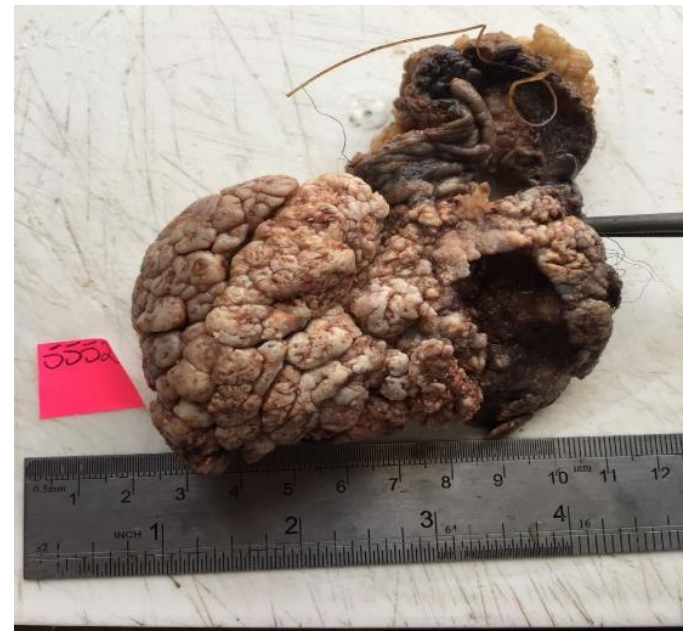

Total view of the tumor under study in the area of pathology

Definitive diagnosis of the patient: CARCINOMA OF SCALING CELLS TYPE VERRUCOSO INFILTRATIVO. Extension of $7 \times 6 \mathrm{~cm}$. Depth of invasion $2.7 \mathrm{~mm}$ in central region 


\section{Conclusions and Recommendations}

We conclude that it has an unknown etiology, the factors that affected its condition are the low socioeconomic level, the precarious and unsanitary conditions in which its environment developed and the background of vulvovaginal condylomatosis. According to histopathological and environmental factors, there are two etiological entities other than squamous cell carcinoma of the vulva:

The ignorance of the people about the terrible consequences that this type of pathologies brings contributes to the affected people, hiding the problem by ignorance or shame, allowing it to increase in size and danger, attacking and deteriorating the health of the people affected. Both the basaloid or verrucose type, related to infection by human papilloma virus (HPV), with vulvar intraepithelial neoplasia (VIN) and keratinizing type, appears predominantly in older women.

After this analysis it is recommended to promote the collection of PAP samples in all cases in which this type of pathology is suspected, in order to achieve timely detection of vulvar cancer and avoid its fatal consequences. And try to increase the information on these pathologies and the importance of being treated in time to prevent the loss of life of patients.

\section{Confidentiality}

The personal data of the patient have been protected as indicated by medical ethics.

\section{Conflict of Interests}

The authors declare that does not exist an interest conflict.

\section{References}

[1] Mayo Clinic. Cáncer vulvar (s/f)https://www.mayoclinic.org/es-es/diseases-conditions/vulvarcancer/symptoms-causes/syc-20368051

[2] Vulvar cancer: Clinical picture, histopathology and survival (1980-2004) Omar de Jesús Bosque Diego, I Rodolfo Delgado Almanza,II Jorge Felipe Montero León, III Roberto Pablo Esperón Noa, IV Juan Mario Silveira Pablos, V Francisco Orlando Aguilar Vela de Oro V http://www.bvs.sld.cu/revistas/cir/vol47_4_08/cir08408.pdf

[3] Gómez-Alarcón A, Gómez-García MT, García-de la-Torre JP, Del Valle-Morón M, AronesCollantes MA, González-de Merlo G. caso clínico Ginecol Obstet Mex. 2016 mar;84(3):172-179 Carcinoma epidermoide de vulva en mujer joven con VPH negative http://www.medigraphic.com/pdfs/ginobsmex/gom-2016/gom163g.pdf

[4] Judson PL, Habermann EB, Baxter NN, Durham SB, Virnig BA. Trends in the incidence of invasive and in situ vulvar carcinoma. Obstet Gynecol 2006; 107:1018-22. https://www.ncbi.nlm.nih.gov/pubmed/16648405

[5] Jones IS, Crandon A, Sanday K. Squamous Cell Carcinoma of the Vulva: A Comparison between Women 35 Years or Younger and 90 Years or Older. Journal of Lower Genital Tract Disease 2013;17: 262-272.

[6] Hording U, Daugaard S, Junge J, Lundvall F. Human papilloma viruses and multifocal genital neoplasia. Int J Gynecol Pathol 1996; 15:230-4.

[7] Togo-Peraza JM, Togo-Osuna LR, Montoya-Romero JJ. Carcinoma vulvar in situ en mujer de 19 años, reporte de un caso y revisión de la bibliografía. Ginecol Obstet Mex 2014; 82:558-562. 
[8] J. Bornstein et al. The 2015 International Society for the Study of Vulvovaginal Disease (ISSVD) Terminology of Vulvar Squamous Intraepithelial Lesions. ASCCP JLGTD. 2016. Vol. 127, No. 2: 264-268

[9] E. J. Wilkinson, J. Thomas Cox, M. A. Selim, D. M. O'Connor. Evolution of Terminology for Human-Papillomavirus-Infection-Related Vulvar Squamous Intraepithelial Lesions. JLGTD. 2015; Volume 19, Number 1: 81-87.

[10] Pérez Echemendía M. Ginecología oncológica pelviana. La Habana: Ecimed; 2006:151 http://scielo.sld.cu/scielo.php?script=sci_arttext\&pid=S0864-21412006000300011

*Corresponding author.

E-mail address: xavier.chang@ug.edu.ec/jorge.dahern@ug.edu.ec/alida.vallejol@ug.edu.ec/ ositos_3@yahoo.es 